Analytical Methods

\title{
Behavior of field-applied triadimefon, malathion, dichlorvos, and their main metabolites during barley storage and beer processing
}

\author{
Zhiqiang Kong ${ }^{\mathrm{a}, 1}$, Minmin $\mathrm{Li}^{\mathrm{a}, 1}$, Jieying Chen ${ }^{\mathrm{a}}$, Yuejing Gui ${ }^{\mathrm{a}}$, Yuming Bao ${ }^{\mathrm{a}}$, Bei Fan ${ }^{\mathrm{a}}$, Qiu Jian ${ }^{\mathrm{b}}$, \\ Frédéric Francis ${ }^{c}$, Xiaofeng Dai ${ }^{\mathrm{a}, *}$ \\ a Institute of Food Science and Technology, Chinese Academy of Agricultural Sciences/Key Laboratory of Agro-Products Processing/Laboratory of Agro-products Quality Safety \\ Risk Assessment, Ministry of Agriculture, Beijing 100193, PR China \\ ${ }^{\mathrm{b}}$ Institute of the Control of Agrochemicals, Chinese Ministry of Agriculture, Beijing 100193, PR China \\ ${ }^{\mathrm{c}}$ Functional and Evolutionary Entomology, Gembloux Agro-Bio-Tech, University of Liége, Passage des Déportés 2, 5030 Gembloux, Belgium
}

\section{A R T I C L E I N F O}

\section{Article history:}

Received 27 April 2015

Received in revised form 8 May 2016

Accepted 10 May 2016

Available online 11 May 2016

\section{Keywords:}

Behavior

Pesticide residue

Barley

Beer

Storage

Processing factor

\begin{abstract}
A B S T R A C T
The behavior and fate of 3 pesticides (triadimefon, malathion, and dichlorvos) and the main metabolites (triadimenol and malaoxon) during barley storage or beer processing were assessed using a pilot-plant equipment. The residues of all products were determined using liquid chromatography coupled with tandem mass spectrometry. Field investigation of the dissipation rate kinetics for triadimefon and malathion during storage indicated that their half-life was twice as high when 5 times the recommended dosage was used. Milling had little effect on the removal of dichlorvos and malathion residues, whereas these were substantially removed when the spent grains were filtered after mashing. The calculated processing factors were all $<1$, indicating the residual ratios of dichlorvos and malathion were reduced during the entire process. In conclusion, storage and processing considerably reduced pesticide residue levels in barley and beer; however, greater focus needs to be paid to the toxicity of their metabolites in commercial by-products.
\end{abstract}

๑) 2016 Elsevier Ltd. All rights reserved.

\section{Introduction}

Beer is an extremely popular beverage worldwide, representing the third-most popular drink after water and tea (Nelson, 2005). There is a long tradition of drinking beer in Chinese culture; at present, China ranks first in beer production worldwide (Tang et al., 2013). Several studies have shown that even moderate amounts of beer consumption might have some health benefits (Kondo, 2004). Barley is the major raw material used for beer production; however, because of its high starch and storage protein content, it represents an attractive source of nutrients for insects and microbial pathogens. Therefore, various combinations of pesticides are widely used at several stages of barley cultivation and during post-harvest storage (Navarro, Perez, Navarro, \& Vela, 2007). Hence, traces of these pesticides might remain in the beer produced from the treated ingredients (Navarro \& Vela, 2009), with pesticide residues also possibly originating from other raw materials such as the hops and water used in the production chain. China is the largest user of pesticides in the world, with an annual pesti-

\footnotetext{
* Corresponding author.

E-mail address: daixiaofeng@caas.cn (X. Dai).

1 The authors Zhiqiang Kong and Minmin Li contributed equally to this paper.
}

cide use rate of $4.9 \%$, ranging from $0.76 \times 10^{9} \mathrm{~kg}$ in 1991 to $1.8 \times 10^{9} \mathrm{~kg}$ in 2011. More than $14 \mathrm{~kg} \mathrm{ha}^{-1}$ of pesticides are applied annually in the cultivated land in China compared to 2.2 and $2.9 \mathrm{~kg} \mathrm{ha}^{-1}$ applied in the USA and in France, respectively (Li, Zeng, \& You, 2014). Unsafe pesticide use or misuse practices include the application of pesticides banned by the local government, overspraying, and inappropriate pesticide use.

Triadimefon and malathion are the two main pesticides used during cultivation to protect barley from diseases and pest infestation (Leibovitch, Ma, Maloba, \& Smith, 1992; Navarro, Vela, \& Navarro, 2011; Gu et al., 2010), and malathion and dichlorvos are the main insecticides used at the post-harvest storage stage to protect the grains from stored-product insects (Uygun, Senoz, Ozturk, \& Koksel, 2009; Phillips, Berberet, \& Cuperus, 2000). Jiang et al. investigated the pesticide residues of barley from seven provinces of China; although none of the analyzed pesticides exceeded national standard in China, triadimefon was detected in samples from all seven provinces (Jiang, Hu, Sun, Gu, \& Song, 2010). Regulations have been established regarding the maximum residue levels (MRLs) for these components in cereals (including barley). The MRLs for triadimefon, malathion, and dichlorvos as pesticides are $0.2,8.0$, and $0.1 \mathrm{mg} \mathrm{kg}^{-1}$, respectively (GB 2763-2014). Unfortunately, dichlorvos and malathion have acute toxic effects in 
humans, since they inhibit synaptic acetylcholinesterase in the nervous system (Sultatos, 1994). In addition, triadimefon and malathion cause chronic health toxicity (Ray \& Richards, 2001; Martin et al., 2007), including reproductive, neurological, gene-, immunological, and endocrine-mediated toxicity. Furthermore, malathion creates the active metabolite malaoxon through oxidative sulfuration (Roberts, 1998), and malaoxon is known to be more toxic than its parent malathion (Aker, Hu, Wang, \& Hwang, 2008; US EPA, 2009). Triadimefon might be enzymatically transformed in plants and fungi by the reduction of a carbonyl group to its corresponding alcohol, triadimenol, which is also registered separately as a systemic fungicide having greater fungicidal activity than triadimefon. Previous studies have shown that triadimenol has prominent teratogenic effects and is harmful to the mammalian central nervous system (Menegola, Broccia, Di Renzo, Prati, \& Giavini, 2000). Hence, monitoring trace levels of triadimefon, malathion, dichlorvos, and their metabolites in barley and beer is essential.

Newly harvested barley is generally stored, followed by food processing, including malting, milling, mashing, boiling, cooling, and fermentation, to create beer. During this process, complex physical and chemical properties change, affecting the pesticide concentrations in the barley. Several studies have determined the fate of pesticide residues during storage and processing (Inoue, Nagatomi, Suga, Uyama, \& Mochizuki, 2011; Navarro, Vela, Perez, \& Navarro, 2011). Most processing techniques might reduce the pesticide content in beer products, with residues becoming more concentrated in the final product (Kong et al., 2012) or, in certain cases, forming more toxic by-products or metabolites of the parent pesticide compound that was originally applied to the raw crop (Holland, Hamilton, Ohlin, \& Skidmore, 1994). Uygun, Özkara, Özbey, and Koksel (2007) investigated the residue levels of malathion and fenitrothion during storage and found that malathion remains relatively longer in barley, probably because it penetrates the grain. Miyake, Hashimoto, Matsuki, Ono, and Tajima (2002) investigated the effect of malting on organophosphorous insecticides and azole fungicides and found that some pesticide residues have log Kow values (partition coefficient between n-octanol and water) of $>2$ remaining on malt. Mashing and boiling reduce the concentration of most pesticides; however, different percentages of pesticide residues present on the malt enter the wort after mashing and boiling (Navarro et al., 2011). The ratios of residue levels in processed products and their respective raw products are called processing factors (PFs; BfR., 2010). PFs allow the assessment of dietary intake of related pesticides in processed commodities (Amvrazi \& Albanis, 2008). They are also used for recommending the MRLs in processed products, with an existing codex commodity code, but only if processing increases residue levels (Gonzalez-Rodriguez, Rial-Otero, Cancho-Grande, Gonzalez-Barreiro, \& Simal-Gandara, 2011). However, few studies have focused on establishing a precise value applicable for PFs in beer products. Therefore, elucidating the fate of pesticides and their metabolites during storage and processing is essential to address the risk of pesticide contamination in beer.

This study aimed to investigate the fate and magnitude of malathion and triadimefon and their metabolites (such as malaoxon and triadimenol) in barley under local storage conditions, following their application in different dosages in the field. Further, we determined whether processing affects dichlorvos and malathion levels, which were used as the store pest insecticides in barley, and identified the residues and PFs of these 2 pesticides at each processing stage (including malting, milling, mashing, brewing, cooling, and fermentation). Finally, we predicted the carryover potential of malathion and its metabolite (malaoxon) residues at different processing steps during fermentation. The results of this study might provide baseline information about the toxicity risk of pesticides to beer production, which might allow the establishment of best-management practices.

\section{Materials and methods}

\subsection{Chemicals and reagents}

The analytical standards of triadimefon, triadimenol, malathion, malaoxon, and dichlorvos were purchased from Dr. Ehrenstorfer (LGC Standards; Augsburg, Germany; purity $\geqslant 98.0 \%$ ). Commercial triadimefon $20 \%$ emulsifiable concentrate (EC) was purchased from Jiangsu Sword Agrochemicals Co., Ltd. (Jiangsu, China), malathion $40 \%$ EC was purchased from Shanghai Yanong Pesticide \& Chemical Co., Ltd. (Shanghai, China) and dichlorvos 77.5\% EC was obtained from Henan Chunguang Agrochemicals Co., Ltd. (Henan, China). Acetonitrile, acetone, hydrochloric acid $(\mathrm{HCl})$, anhydrous magnesium sulfate $\left(\mathrm{MgSO}_{4}\right)$, sodium chloride $(\mathrm{NaCl})$, and sodium acetate $(\mathrm{NaAc})$ were of analytical grade and were purchased from Beijing Chemical and Reagent (Beijing, China). Acetonitrile and acetone (chromatography grade) were supplied by Honeywell International Inc. (New Jersey, USA). Ultra-pure water was obtained from a MilliQ system (Bedford, MA, USA).

\subsection{Standard solution}

Standard stock solutions $\left(1.0 \mathrm{mg} \mathrm{mL}^{-1}\right)$ of triadimefon, triadimenol, malathion, malaoxon, and dichlorvos were separately prepared by exactly weighing and dissolving in chromatography grade methanol and were stored at $-20^{\circ} \mathrm{C}$. Working standard solutions containing triadimefon, triadimenol, malathion, malaoxon, and dichlorvos $\left(0.001,0.005,0.01,0.1,1,5\right.$, and $\left.10 \mu \mathrm{g} \mathrm{mL}^{-1}\right)$ were prepared by diluting the stock solution. A second set of working standard solutions was matrix standards that were prepared by diluting the stock solution or a working matrix standard by using the extract of a clean control. Both solvent and matrix standards were analyzed in the same analytical batch. All standard solutions were stored in the dark at $4{ }^{\circ} \mathrm{C}$.

\subsection{Field trials}

Three separate field experiments were conducted on barley (Hordeum vulgare L.; cultivated variety: Yangnong 3) at Sheyang Farm, located in the city of Yancheng, in the northeast of Jiangsu Province, China. The barley samples from all 3 experiments were investigated and determined to be free of the 2 target pesticides and their metabolites. Triadimefon 20\% EC and malathion 40\% EC were applied at the recommended dosage (RD; $600 \mathrm{~g}$ active ingredient hectare ${ }^{-1}$ for triadimefon and $480 \mathrm{~g}$ active ingredient hectare $^{-1}$ for malathion) in field 1 . In field 2, 5-fold of the recommended dosage (FD; $3000 \mathrm{~g}$ active ingredient hectare ${ }^{-1}$ for triadimefon and $2400 \mathrm{~g}$ active ingredient hectare ${ }^{-1}$ for malathion) was applied to ensure sufficient primary deposit of pesticide for the following storage processing. Field 3 was used as the control, on which neither of the 2 target pesticides was applied. The barley in fields 1 and 2 was sprayed twice at 14 and 7 days before harvest. Each treatment, including the untreated control, was replicated 3 times in randomized blocks. Barley samples were placed in polyethylene bags and transported to the laboratory for the next stage of the study.

\subsection{Storage stability}

The barley obtained from fields 1,2 , and 3 was stored in 3 separate small-scale models $(50 \mathrm{~cm}$ (length) $\times 50 \mathrm{~cm}$ (width) $\times 40 \mathrm{~cm}$ (height)) of a storage vessel at ambient temperatures. The vessels 
were made of thin metal sheets and used for the laboratory storage experiments. For the stability studies of triadimefon and malathion in stored barley, barley samples were collected from each plot on days $0,1,3,5,7,10,14,18,27,39$, and 53 . The samples were stored in individual polyethylene bags and placed in a refrigerator at $-20^{\circ} \mathrm{C}$ until analysis.

\subsection{Beer processing}

Whether processing affects dichlorvos and malathion levels, which are used as store pest insecticides in barley, was investigated by preparing $500 \mathrm{mg}$ malathion $40 \% \mathrm{EC}$ and $260 \mathrm{mg}$ dichlorvos $77.5 \%$ EC mixture in $100 \mathrm{~mL}$ water. This mixture was evenly sprayed over $10 \mathrm{~kg}$ barley that had been collected from field 3 . Five-spot-sampling method was applied to check the homogeneity of the pesticide on the barley samples. The starting point of dichlorvos and malathion was $20 \mathrm{mg} \mathrm{kg}^{-1}$, and then the samples were immediately sent to the workshop for processing.

In general, the production procedures of beer include six steps: malting, milling, mashing, boiling, cooling, and fermentation. The processing steps and sampling points are shown in Supplementary Fig. 1. In this study, samples were collected at different processing steps to determine the amount of dichlorvos and malathion residues during the course of the processing procedure. The detailed processing procedure is as follows.

Process 1. Malting: For this, $10 \mathrm{~kg}$ high-quality barley (10\% moisture) that had been treated with dichlorvos and malathion was selected and placed in a steep vat of water for about $40 \mathrm{~h}$. Next, the barley was spread out on the floor of the germination room for about 3 days where rootlets began to form. After germination, the green malt was dried on metal racks in the kiln house at $50{ }^{\circ} \mathrm{C}$.

Process 2. Milling: All the malted barley was selected for milling by using a malt mill machine (Gongda Machine Co., Ltd. Shandong, China).

Process 3. Mashing: The milled barley was dropped into $50 \mathrm{~L}$ warm water $\left(\mathrm{pH}\right.$ 7.6; dissolved solids $=485 \mathrm{mg} \mathrm{L}^{-1}$; trichlormethane $=39.1 \mu \mathrm{g} \mathrm{L}^{-1}$; pesticides below the detection limit) at $53{ }^{\circ} \mathrm{C}$ for $70 \mathrm{~min}$, and then gradually heated to around $66{ }^{\circ} \mathrm{C}$ in a large cooking vessel called the mash tun for $80 \mathrm{~min}$. In this mash tun, the grain and heated water mix created a cereal mash that dissolved the starch into the water and transformed it to sugar.

Process 4. Boiling: The spent grains were filtered out, and the wort was diluted to $12^{\circ}$ Brix by using water for boiling, which involves many technical processes and chemical reactions. The wort was boiled at $140{ }^{\circ} \mathrm{C}$ for $90 \mathrm{~min}$ to sterilize and concentrate it. During this stage, certain types of hops and carrageenan were added at different times during boiling to adjust bitterness or aroma and to help with preservation.

Process 5. Cooling: The wort is rapidly transferred from the brew kettle through a device to filter out the hops, and then onto a heat exchanger for cooling. Rapidly cooling the wort to a point where yeast can be safely added is important. The hopped wort was saturated with air, which is essential for the growth of yeast in the next stage.

Process 6. Fermentation: The cooled wort was passed through the heat exchanger and transferred to the fermentation tank; next, lager yeast was added at $1.5 \times 10^{7}$ cells $\mathrm{mL}^{-1}$. The fermentation process requires 10 days and transforms the wort to beer.

\subsection{Extraction and purification procedures}

\subsubsection{Extraction and purification of barley samples}

A $5 \mathrm{~g}$ portion of homogenized sample was weighed into a $50 \mathrm{~mL}$ PTFE centrifuge tube. A 3-mL volume of pure water was added and the volume shaken for $1 \mathrm{~min}$. Then, $20 \mathrm{~mL}$ acetonitrile was added, and the mixture was placed on a Geno/Grinder mechanical shaker (SPEX SamplePrep, USA) for 3 min at 1200 strokes min $^{-1}$. A total of $2 \mathrm{~g}$ anhydrous $\mathrm{MgSO}_{4}$ and $1 \mathrm{~g} \mathrm{NaCl}$ was added and vortexed using an XW-80A vortex (Kirin Medical Instrument, China) at full speed for $3 \mathrm{~min}$, and then the tube was centrifuged using a TG16-WS centrifuge (Xiangyi Centrifuge Machines, China) for $5 \mathrm{~min}$ at a relative centrifugal force (RCF) of $2077 \mathrm{~g}$. Subsequently, $8 \mathrm{~mL}$ upper layer (acetonitrile) was collected in a round-bottom flask and concentrated almost to dryness by using a rotary evaporator (Yarong Machiners, China) at $35^{\circ} \mathrm{C}$. The residue was reconstituted in $2 \mathrm{~mL}$ acetonitrile and transferred to a $2.5 \mathrm{~mL}$ centrifuge tube containing $50 \mathrm{mg}$ PSA plus $150 \mathrm{mg}$ anhydrous $\mathrm{MgSO}_{4}$. The mixture was vortexed at full speed for $1 \mathrm{~min}$ and briefly centrifuged. Subsequently, $1 \mathrm{~mL}$ of the upper layer (acetonitrile) was filtered with a $0.22 \mathrm{~mm}$ syringe filter for HPLC-MS analysis.

\subsubsection{Extraction and purification of beer samples}

For this, $10 \mathrm{~mL}$ beer samples were measured into a $50 \mathrm{~mL}$ PTFE centrifuge tube. Then, $600 \mu \mathrm{L}$ of $1 \mathrm{~mol} \mathrm{~L}^{-1} \mathrm{HCl}$ was added to adjust the $\mathrm{pH}$ to 2.0. Subsequently, $10 \mathrm{~mL}$ acetonitrile was added, and the mixture was placed on a Geno/Grinder mechanical shaker for $3 \mathrm{~min}$ at 1200 strokes $\mathrm{min}^{-1}$. Next, $4 \mathrm{~g}$ of anhydrous $\mathrm{MgSO}_{4}, 1 \mathrm{~g}$ $\mathrm{NaCl}$, and $1 \mathrm{~g} \mathrm{NaAc}$ were added and vortexed using an XW-80A vortex at full speed for $3 \mathrm{~min}$. The tube was then centrifuged with a TG16-WS centrifuge for $5 \mathrm{~min}$ at RCF $2077 \mathrm{~g}$. Subsequently, $1.5 \mathrm{~mL}$ of the upper layer (acetonitrile) was transferred to a 2.5 $\mathrm{mL}$ centrifuge tube containing $50 \mathrm{mg}$ PSA plus $150 \mathrm{mg}$ anhydrous $\mathrm{MgSO}_{4}$. The mixture was vortexed at full speed for $1 \mathrm{~min}$ and briefly centrifuged. Then, $1 \mathrm{~mL}$ of the upper layer (acetonitrile) was filtered with a $0.22-\mathrm{mm}$ syringe filter for HPLC-MS analysis.

\subsection{Instrumentation and LC-MS/MS analytical conditions}

Chromatographic separation was performed using an isocratic system by using 1260 HPLC system equipped with an analytical column Agilent Poroshell 120SB-C18 (4.6 mm $\times 150 \mathrm{~mm}$, $2.7 \mu \mathrm{m})$. The HPLC-MS/MS system was controlled by a MassHunter workstation (Agilent Technologies, CA, USA). The LC parameters were as follows: mobile phase $A$ : water containing $0.1 \%$ formic acid $(\mathrm{v} / \mathrm{v})$ and $0.01 \mathrm{~mol} \mathrm{~L}^{-1}$ ammonium formate; mobile phase $\mathrm{B}$ : methanol containing $0.1 \%$ formic acid $(\mathrm{v} / \mathrm{v})$; isocratic elution with mobile phase A/mobile phase $\mathrm{B}(30 / 70, \mathrm{v} / \mathrm{v})$; injection volume, $3 \mu \mathrm{L}$; flow rate, $0.4 \mathrm{~mL} \mathrm{~min}^{-1}$.

An Agilent 6410 triple quadrupole mass spectrometer in the positive electrospray ionization (ESI+) mode was used for the analysis of the 5 pesticides. The MS source conditions were as follows: gas flow, $10 \mathrm{~L} \mathrm{~min}{ }^{-1}$; gas temperature, $300{ }^{\circ} \mathrm{C}$; nebulizer pressure, $40 \mathrm{psi}$; capillary voltage, $4000 \mathrm{~V}$. All other MS-MS parameters were separately optimized for each target compound and are listed in Supplementary Table 1.

\subsection{Recovery assay}

Untreated barley samples were fortified, on average, at 0.001 , $0.05,0.2,1.0$, and $10.0 \mathrm{mg} \mathrm{kg}^{-1}$, by adding intermediate pesticide working solutions (mixture of triadimefon, triadimenol, malathion, malaoxon, and dichlorvos solutions) in methanol. Untreated beer samples were spiked with appropriate volumes of pesticide working solutions at levels of $0.001,0.05,0.2,1.0$, and $10.0 \mathrm{mg} \mathrm{L}^{-1}$ (Supplementary Table 1 ), with 5 replicates for each concentration. Before the extraction step, the spiked samples in the tubes were vortexed for $30 \mathrm{~s}$ and allowed to settle for $2 \mathrm{~h}$ at room temperature to distribute evenly the pesticide and to ensure complete interaction with the sample matrix. The samples were then processed according to the described procedure. The recoveries obtained with the extracted spiked samples were compared against those of the 
matrix-matched calibration solutions. Calibration curves in the matrix were prepared using this method, and the data were automatically corrected for analytical recovery.

\subsection{Statistical analysis}

Dissipation studies of pesticide residues were performed using linear regression. Data were statistically evaluated using one-way analysis of variance by using Origin 8.0. When significant differences were found, the least significant difference (LSD) test was used to determine the differences among the means. All the values are reported as means \pm standard deviation (SD) of 5 replicates.

\section{Results and discussion}

\subsection{Method validation}

Identification and quantification of triadimefon, triadimenol, malathion, malaoxon, and dichlorvos was based on their HPLC retention times, and the peak areas were compared against the standard calibration curves. A typical chromatogram is shown in Fig. 1. The limits of detection (LODs) and the limits of quantitation (LOQs) for triadimefon, triadimenol, malathion, malaoxon, and dichlorvos were considered to be the concentrations produced at a signal-to-noise $(\mathrm{S} / \mathrm{N})$ ratio of 3 and 10 , respectively. Further, the data for LOD and LOQ were retained to the first place after the decimal point according to the round-off principle. The LODs and LOQs were estimated from the chromatogram corresponding to the lowest point used in the matrix-matched calibration. In this study, the LOD for the 5 analytes ranged between 0.1 and $0.3 \mu \mathrm{g} \mathrm{kg}^{-1}$, whereas the LOQ ranged between 0.5 and $1.0 \mu \mathrm{g} \mathrm{kg}^{-1}$ (Supplementary Table 2).

The samples were prepared using a modified QuEChERS method. The accuracy was evaluated by determining the spike recoveries at various levels in a complex matrix. The recoveries of triadimefon, triadimenol, malathion, malaoxon, and dichlorvos in the barley and beer matrix were within $83.6 \%-112.8 \%$ at the tested concentrations (Supplementary Table 3), which were within the range expected for residue analysis based on the recommendations of Document SANCO/12571/2013 (European Commission, 2013). The reproducibility of the recovery results was high, as indicated by the relative standard deviations (RSDs) ranging from 1.2 to 10.3 , confirming that the method used was sufficiently reliable for pesticide analysis.

Two sets of calibration curves were used to determine the effects of the matrix. One set of calibration standards was prepared using in the pure solvent (methanol). The other set was prepared using the extracts of the control samples (known as matrix standards). The matrix effect (ME) was calculated using the following equation:

$\operatorname{ME}(\%)=[$ slope $($ matrix $)-$ slope $($ solvent $)] /$ slope $($ solvent $) \times 100$

where slope (matrix) and slope (solvent) are the slopes of the calibration curves of the matrix and solvent standards, respectively (Zhang et al., 2015; Jang et al., 2014). Depending on the decrease or increase in the percentage of the slope, different matrix effects were observed. Slope percentages between $-20 \%$ and $+20 \%$ represented mild signal suppression or enhancement effects, respectively. Slope percentages between $-50 \%$ and $+50 \%$ represented medium effects. Slope percentages below $-50 \%$ and above $+50 \%$ represented strong effects of signal suppression and enhancement, respectively. Noticeable signal suppression and enhancement differences occurred for the 5 analytes in the 2 matrices, because the slope ratios of matrix/ACN ranged from 0.1 to 1.4 and slope values ranging between $-38.1 \%$ and $+25.4 \%$ (Supplementary Table 2 ). Therefore, using matrix-matched calibration solutions was necessary to compensate for errors associated with matrix-induced suppression and enhancement effects.

\subsection{Stability of triadimefon and malathion in barley during storage}

Grains are frequently stored for long periods at ambient temperatures in bulk silos before being processed (Holland et al., 1994). Changes in the concentrations of triadimefon and malathion

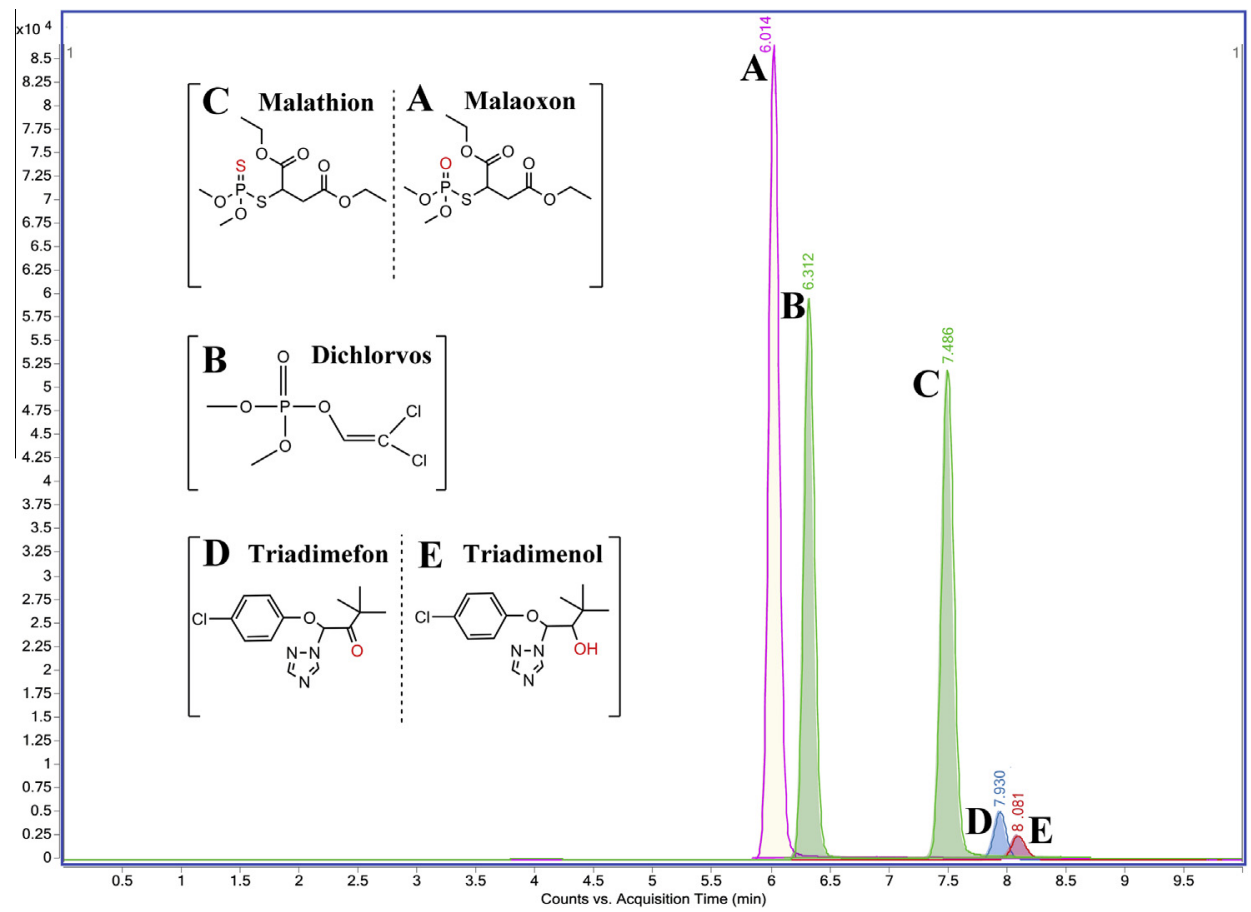

Fig. 1. Typical total ion current (TIC) chromatograms and structures of 5 standard pesticide solutions at concentrations of $500 \mu \mathrm{L}^{-1}$. 
and their metabolites, triadimenol and malaoxon, during storage are shown in Table 1 and Fig. 2. Triadimefon was degraded to triadimenol in fields 1 and 2, resulting in a considerable amount of triadimenol residues remaining in the barley. The content of the metabolite triadimenol in fields 1 and 2 was $898.9 \mu \mathrm{g} \mathrm{kg}^{-1}$ and $4033.7 \mu \mathrm{g} \mathrm{kg}^{-1}$, respectively, which was more than that of its par- ent triadimefon residues ( 808.2 and $3840.5 \mu \mathrm{g} \mathrm{kg}^{-1}$, respectively). This difference might be because triadimefon is efficiently degraded to triadimenol under field conditions. The degradation trends of triadimefon in barley followed the first order kinetics $\left(C_{t}=C_{0} \mathrm{e}^{-\mathrm{rt}}\right)$, where $C_{t}$ is the concentration at time $\mathrm{t}$ (days) after treatment, $C_{0}$ is the initial concentration ( $0 \mathrm{~d}$ obtained barley),

Table 1

Amounts of triadimefon and malathion and their metabolites triadimenol and malaoxon $\left(\mu \mathrm{g} \mathrm{kg}^{-1}\right)$ recovered from barley after storage.

\begin{tabular}{|c|c|c|c|c|c|c|c|c|}
\hline \multirow[t]{2}{*}{ Times (days) } & \multicolumn{2}{|c|}{ Triadimefon } & \multicolumn{2}{|l|}{ Triadimenol } & \multicolumn{2}{|l|}{ Malathion } & \multicolumn{2}{|l|}{ Malaoxon } \\
\hline & $\mathrm{RD}$ & FD & $\mathrm{RD}$ & FD & $\mathrm{RD}$ & FD & $\mathrm{RD}$ & FD \\
\hline 0 & $808 \pm 81$ & $3840 \pm 269$ & $899 \pm 49$ & $4034 \pm 73$ & $40.1 \pm 3.8$ & $274.2 \pm 12.4$ & $2.48 \pm 0.441$ & $10.5 \pm 0.472$ \\
\hline 1 & $749 \pm 22$ & $3568 \pm 66$ & $905 \pm 40$ & $4294 \pm 611$ & $33.7 \pm 4.7$ & $210.9 \pm 31.1$ & $2.50 \pm 0.235$ & $8.3 \pm 0.281$ \\
\hline 3 & $730 \pm 90$ & $3204 \pm 45$ & $923 \pm 86$ & $5510 \pm 512$ & $25.4 \pm 2.9$ & $171.6 \pm 18.6$ & $1.33 \pm 0.07$ & $6.9 \pm 0.591$ \\
\hline 5 & $589 \pm 52$ & $3347 \pm 328$ & $1337 \pm 84$ & $5715 \pm 359$ & $23.1 \pm 3.1$ & $143.9 \pm 6.4$ & $0.89 \pm 0.169$ & $5.1 \pm 0.602$ \\
\hline 7 & $529 \pm 42$ & $2898 \pm 42$ & $1149 \pm 111$ & $5168 \pm 321$ & $14.6 \pm 3.2$ & $135.8 \pm 19.2$ & $0.75 \pm 0.141$ & $3.1 \pm 0.417$ \\
\hline 10 & $575 \pm 86$ & $2808 \pm 54$ & $1235 \pm 84$ & $5574 \pm 178$ & $14.0 \pm 2.46$ & $129.9 \pm 6.3$ & $0.74 \pm 0.025$ & $2.9 \pm 0.129$ \\
\hline 14 & $429 \pm 24$ & $2519 \pm 96$ & $1185 \pm 61$ & $5978 \pm 210$ & $12.1 \pm 2.59$ & $87.8 \pm 8.3$ & $0.31 \pm 0.037$ & $2.5 \pm 0.328$ \\
\hline 18 & $397 \pm 21$ & $2415 \pm 100$ & $1200 \pm 50$ & $6197 \pm 565$ & $9.8 \pm 1.74$ & $60.1 \pm 7.8$ & $<$ LOD & $1.8 \pm 0.251$ \\
\hline 27 & $338 \pm 31$ & $2302 \pm 136$ & $1151 \pm 11$ & $6068 \pm 139$ & $8.6 \pm 1.48$ & $59.9 \pm 9.3$ & $<$ LOD & $1.3 \pm 0.083$ \\
\hline 39 & $232 \pm 55$ & $1855 \pm 106$ & $1202 \pm 8$ & $6121 \pm 456$ & $7.2 \pm 0.79$ & $30.2 \pm 4.5$ & $<$ LOD & $<$ LOD \\
\hline 53 & $189 \pm 3.8$ & $1780 \pm 99$ & $1130 \pm 39$ & $6441 \pm 189$ & $3.8 \pm 1.1$ & $30.7 \pm 1.5$ & $<$ LOD & $<$ LOD \\
\hline
\end{tabular}

Values are mean \pm standard deviation.

$\mathrm{RD}$ : recommended dosage.

FD: fivefold of the recommended dosage.

- recommended dosage

- fivefold of recommended dosage
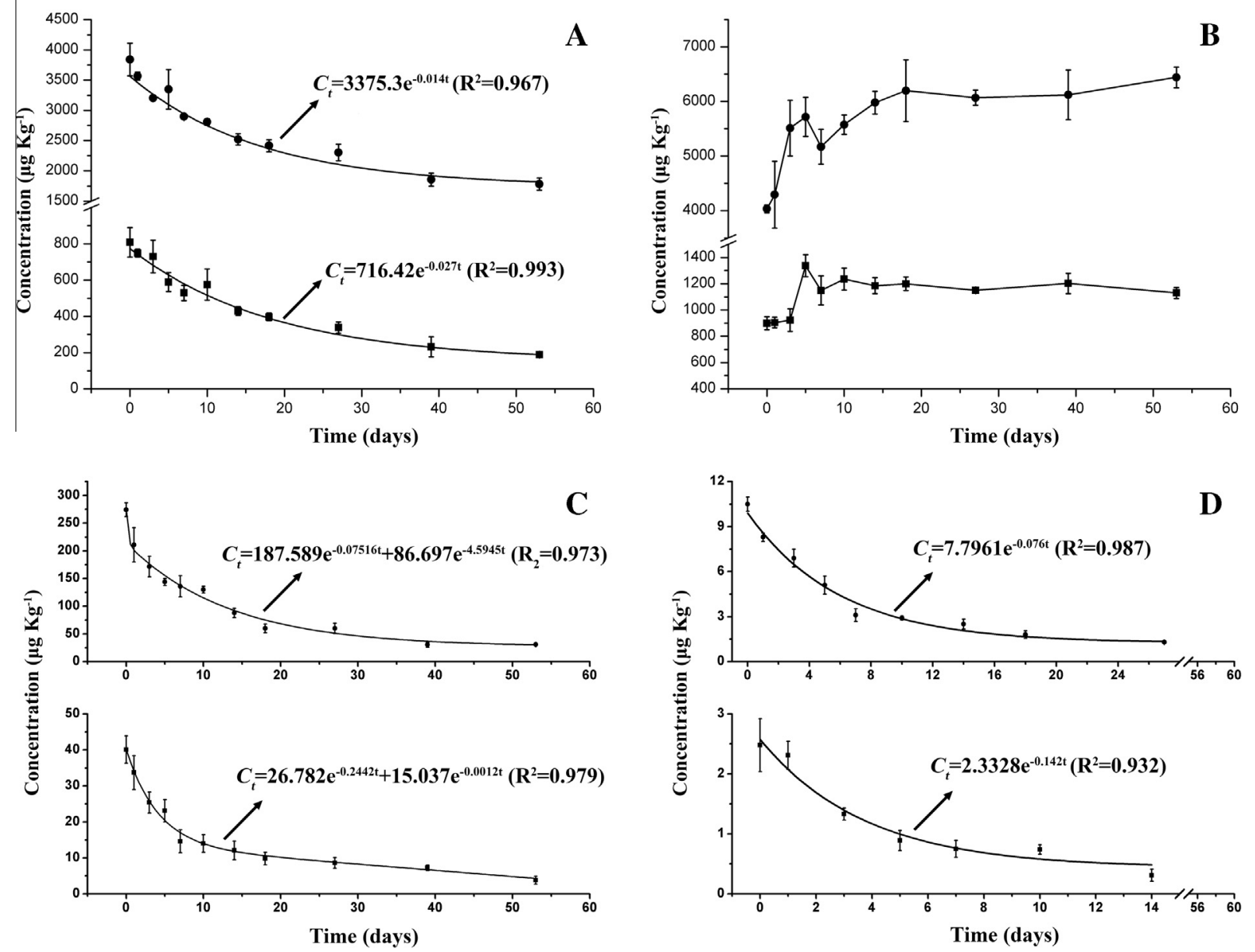

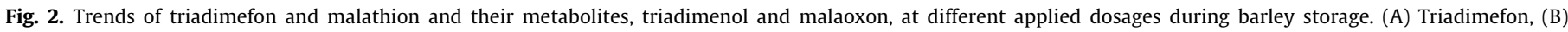
Triadimenol, (C) Malathion, (D) Malaoxon. 
and $r$ is the first order rate constant ( $1 /$ day). The degradation halflife $\left(t_{1 / 2}\right)$ of triadimefon in each experiment was obtained as $t_{1 / 2}=\operatorname{In}(2) / \mathrm{r}$. Thus, the calculated half-life of triadimefon from field 1 (RD) was 25.6 days, with a dynamic degradation equation of $C_{t}=716.42 \mathrm{e}^{-0.027 t}\left(\mathrm{R}^{2}=0.993\right)$. However, the triadimefon from field 2 (FD) was more persistent than that from field 1 (RD), with a 49.5 day half-life and degradation equation of $C_{t}=3375.3 \mathrm{e}^{-0.014 t}$ $\left(R^{2}=0.967\right)$. Long half-lives with higher levels of triadimefon are probably because of the reduced biological reaction activity in stored barley. However, the behavior of triadimenol did not follow the first order kinetics, with residue concentrations in barley slightly increasing during the first 5 days of storage. Although triadimenol levels dropped after 5 days, the residue levels generally followed an increasing trend over the last 2 months of storage. This increase resulted in relatively more triadimenol remaining in the barley at the end of storage than at the start of storage (Fig. 2B). This phenomenon might be attributed to the metabolism of triadimefon to triadimenol during storage. However, studies on the comparative degradation of this metabolite in stored barley are not available to confirm this hypothesis. Our results also indicated that the method of pesticide application (i.e., pesticides applied at high dose) had a major impact on the persistence of residues in barley.

The residue levels of malathion and malaoxon in barley were considerably lower than those of triadimefon and triadimenol (Table 1). The residues analysis showed that $5.8 \%$ and $3.8 \%$ of malathion were degraded to malaoxon in fields 1 and 2, respectively. The residues of malathion in barley rapidly dissipated during the first 2 weeks of storage (Fig. 2C), after which they decreased at a slower rate until the end of storage. In all the cases, the residue data had the best fit to a two-compartment $1 \mathrm{st}+1 \mathrm{st}$ order kinetics model $\left(R^{2}>0.99\right)$. Thus, partitioning the residues into 2 phases was possible. More than $50 \%$ of the initial deposits of malathion dissipated within 7 days, with half-lives of 5.8 days for RD and 7.0 days for FD (Fig. 2C). However, the degradation trends of malaoxon applied at different doses on barley fitted the first order kinetics pattern, but at a different rate of degradation. Malaoxon half-life values for the RD and FD treatments from the first order model were 4.9 days and 9.1 days, respectively. Fortunately, malaoxon was not observed in barley at the end of storage. These results are consistent with those obtained for stored wheat by Matthews (1990). In contrast, in this study, considerably lower levels of malaoxon were found compared to the very high levels reported in stored barley samples by Uygun et al. (2007). This difference might be attributed to the fact that very little malathion was degraded to malaoxon in barley during storage.

\subsection{Effects of the processing steps on dichlorvos and malathion levels}

Barley is frequently stored for long periods at ambient temperatures in bulk silos, where dichlorvos and malathion might be applied post-harvest to reduce losses caused by store pests. The exposure of ultimate human beer consumers to these pesticides and ways of reducing pesticide levels were estimated by obtaining knowledge about the fate of dichlorvos and malathion during beer production.

The observed changes in the concentrations of dichlorvos and malathion during beer processing are shown in Table 2. After the malting process, the mean losses of dichlorvos and malathion were $11 \%$ and $9 \%$, respectively. These results indicate that their concentrations slightly decreased during the malting process. The malting process prepares barley for use in brewing and includes 3 main stages: steeping, germination, and kilning. These processes involve heat treatment, which decreases the dichlorvos and malathion content. Despite this, Navarro et al. (2011) and Miyake et al. (2002) indicated that the percentage of certain fungicides (such
Table 2

Amount of dichlorvos and malathion residues $\left(\mu \mathrm{g} \mathrm{kg}^{-1}\right.$ for solid samples and $\mu \mathrm{g} \mathrm{L}^{-1}$ for liquid samples) recovered after various processes of beer production.

\begin{tabular}{lll}
\hline Samples & Dichlorvos & Malathion \\
\hline Raw barley & $19763.3^{\mathrm{a}} \pm 127.2$ & $19780.0^{\mathrm{a}} \pm 6564.5$ \\
Malted barley & $17556.7^{\mathrm{b}} \pm 80.2$ & $18073.3^{\mathrm{ab}} \pm 394.1$ \\
Milled barley & $16243.3^{\mathrm{b}} \pm 90.1$ & $16836.7^{\mathrm{b}} \pm 6059.6$ \\
Wort & $1806.7^{\mathrm{c}} \pm 53.9$ & $581.7^{\mathrm{c}} \pm 76.8$ \\
Spent grains & $5403.3^{\mathrm{d}} \pm 85.0$ & $8786.5^{\mathrm{d}} \pm 28.829$ \\
Hot wort & $1076.7^{\mathrm{e}} \pm 40.1$ & $456.7^{\mathrm{e}} \pm 4242.3$ \\
Cooled wort & $998.6^{\mathrm{e}} \pm 65.9$ & $450.3^{\mathrm{e}} \pm 1817.5$ \\
Beer & $<$ LOD & $<$ LOD \\
\hline
\end{tabular}

Values are mean \pm standard deviation

${ }^{a-e}$ Values with the different letters are significantly different $(p<0.05)$.

as myclobutanil, propiconazole, and triflumizole) increase during this process, which might be attributed to the differences in chemical properties of different pesticides.

Milling involves cracking grain that a brewer selected for a particular batch of beer.

Milling had little effect on the removal of dichlorvos and malathion residues (Table 2). The milling process leads to the release of enzymes and acids that might increase the rate of hydrolytic and other degradation processes of dichlorvos and malathion residues. However, most pesticides are relatively stable in acidic tissue homogenates for moderate periods of time during food preparation (Holland et al., 1994).

During mashing, soluble substances (such as starches, amino acids, and peptides) that were released during the malting stage were extracted into the liquid fraction and separated from the residual solid particles (spent grains). Although the concentrations of dichlorvos and malathion in the milled barley were almost the same, most of the malathion was eliminated by this process, whereas the dichlorvos level was remarkably reduced. Their levels decreased by $89 \%$ and $97 \%$, respectively, after mashing. In addition, very low quantities of malathion residues were present in wort (Table 2). This could be attributed to the differences in the physico-chemical properties of dichlorvos and malathion, including water-octanol partition coefficients and different log Kow values reported in the literature (i.e., 1.9 and 2.75 for dichlorvos and malathion, respectively) (Tomlin, 2006). Similar results have also been reported by other researchers (Navarro et al., 2011; Inoue, Nagatomi, Suga, Uyama, \& Mochizuki, 2011; Regueiro, LopezFernandez, Rial-Otero, Cancho-Grande, \& Simal-Gándara, 2015), who suggested that the degree of the log Kow of pesticides affects the amount that remains in the unhopped wort. As a general rule, about $200 \mathrm{~g}$ of grain is used to produce $1 \mathrm{~L}$ of wort at $12^{\circ} \mathrm{P}$, although this amount varies according to whether higher or lower alcoholic content is desired (Navarro et al., 2011). All residues present in the grain and the wort had a density of $1.01 \mathrm{~g} \mathrm{~mL}^{-1}$; hence, even the complete transfer of all residues to the beer would result in the residues undergoing dilution by a factor of 5 . Thus, an $80 \%$ decrease in dichlorvos and malathion residues during wort preparation would be expected. Our results indicated that dichlorvos and malathion were removed during the mashing process (Table 2). In contrast, relatively high amounts of malathion were retained in spent grain. Similar findings were obtained by Inoue et al. (2011), who showed that a higher log Kow value tends to be adsorbed more readily onto spent grain.

The carryovers for dichlorvos and malathion in hot wort are shown in Table 2. Their amounts in hot wort declined by $40 \%$ and $21 \%$, respectively. Processes involving heat treatment cause an increase in volatilization, hydrolysis, and degradation of other chemicals, resulting in the reduction of residue levels (Holland et al., 1994). However, some fungicides are thermally stable at temperatures higher than $100{ }^{\circ} \mathrm{C}$ (Navarro, Perez, Vela, Mena, \& 
Table 3

The processing factors for dichlorvos and malathion after different processes of beer production.

\begin{tabular}{lll}
\hline \multirow{2}{*}{ Treatment } & Processing factors (PFs) & \\
\cline { 2 - 3 } & Dichlorvos & Malathion \\
\hline Malting & 0.89 & 0.91 \\
Milling & 0.93 & 0.93 \\
Mashing & 0.11 & 0.03 \\
Boiling & 0.60 & 0.79 \\
Cooling & 0.93 & 0.98 \\
Fermentation & - & - \\
\hline
\end{tabular}

Navarro, 2005). A very small decrease in residue content of dichlorvos and malathion was recorded after the wort was cooled to room temperature.

Fermentation is a simple process that reduces pesticide residues (Ruediger, Pardon, Sas, Godden, \& Pollnitz, 2005). The final beer product was free of dichlorvos and malathion residues (Table 2) This result might be because yeast partially degrades pesticides or absorbs them during fermentation. For instance, Navarro, Perez, Navarro, Mena, and Vela (2006) showed that the residues of dinitroaniline herbicides were not present in young beer fermented with bottom-yeasts.

\subsection{Processing factors and exposure assessment}

The Joint FAO/WHO Meeting on Pesticide Residues (JMPR) evaluates food processing data on residue behavior, where significant residues are found in plant or plant products that are processed into food. Depending on the effect of residue levels and the amount of residues that are present in various processed products, the JMPR (FAO/WHO, 2006) and OECD (OECD., 2008) consider and calculate PFs as follows:

\section{PFs $=\frac{\text { residue level in processed commodity }}{\text { residue level in the RAW or commodity to be processed }}$}

$\mathrm{PF}$ values of $<1$ (=reduction factor) indicate a reduction in the amount of residues in the processed commodity, whereas values of $>1$ (=concentration factor) indicate the concentration effect of the processing procedures (Timme \& Walz-Tylla, 2004). The calculated PFs for dichlorvos and malathion after processing are shown in Table 3 . The results show that all PFs were $<1$, indicating that their residual ratios are reduced during the entire process. The mashing PFs of dichlorvos and malathion were 0.11 and 0.03 , respectively, indicating that this process remarkably reduces their residues in the wort. Therefore, if barley containing these 2 pesticide residues at levels lower than the assessed MRL is used to produce beer by using this method, the beer could be directly consumed.

Since large amounts of dichlorvos and malathion residues become deposited on the spent grains, the commercial byproduct safety of barley remains a concern considering that barley is used as a nutritive component in animal feed and health food supplements (Pettersson, Graham, \& Aman, 1991).

\section{Conclusions}

This study investigated the behavior and fate of triadimefon, malathion, dichlorvos, and their metabolites (triadimenol and malaoxon) in barley and beer products during storage, malting, milling, mashing, boiling, cooling, and fermentation. Triadimefon and malathion were degraded to triadimenol and malaoxon in the field before harvesting, and these 2 pesticides exhibited different modeled degradation rates. Higher levels of triadimefon and malathion have longer half-lives, which might be due to the low- ered biological activity of stored barley. However, longer halflives raise food safety issues. The concentrations of dichlorvos and malathion residues were significantly lower in beer after processing. Many factors could affect the removal rate of pesticide residues, such as the chemical properties of pesticides and processing procedures. Our results indicated that the PFs of dichlorvos and malathion were $<1$ after the various processing steps. Mashing had a major influence on the removal of dichlorvos and malathion residues, although a large percentage of these pesticides was retained in the spent grain. Malting, milling, boiling, and fermentation also reduced the residual content of these pesticides during beer processing, but at considerably lower levels. Therefore, future studies need to focus on maintaining beer quality and guaranteeing the safety of its commercial by-products when spent grains are used as animal feed and health food supplements.

\section{Acknowledgments}

This work was financially supported by National Natural Science Foundation of China (31301477 and 31401580).

\section{Appendix A. Supplementary data}

Supplementary data associated with this article can be found, in the online version, at http://dx.doi.org/10.1016/j.foodchem.2016. 05.058.

\section{References}

Aker, W. G., Hu, X., Wang, P., \& Hwang, H. M. (2008). Comparing the relative toxicity of malathion and malaoxon in blue catfish Ictalurus furcatus. Environmental Toxicology, 23(4), 548-554.

Amvrazi, E. G., \& Albanis, T. A. (2008). Multiclass pesticide determination in olives and their processing factors in olive oil: comparison of different olive oil extraction systems. Journal of Agricultural and Food Chemistry, 56(14), $5700-5709$.

BfR. (2010). Compilation on processing factors for pesticide residues. http://www. bfr.bund.de/cd/579.

European Commission. (2013). Document No. SANCO/12571/2013. Guidance document on analytical quality control and validation procedures for pesticide residues analysis in food and feed.

FAO/WHO (2006). Updating the principles and methods of risk assessment: Mrls for pesticides and veterinary drugs. Rome: FAO.

GB 2763-2014 (2014). National food safety standard-maximum residue limits for pesticides in food. Standardization administration of the people's republic of china. Beijing: Standards Press of China (in Chinese).

Gonzalez-Rodriguez, R. M., Rial-Otero, R., Cancho-Grande, B., Gonzalez-Barreiro, C., \& Simal-Gandara, J. (2011). A review on the fate of pesticides during the processes within the food-production chain. Critical Reviews in Food Science and Nutrition, 51(2), 99-114.

Gu, F., Jiang, W., Hu, J., Sun, Z., Ma, Y., \& Gao, J. (2010). Pesticide residues in malting barley during process. Food and Fermentation Industries, 36(5), 90-94 (in Chinese).

Holland, P., Hamilton, D., Ohlin, B., \& Skidmore, M. (1994). Effects of storage and processing on pesticide residues in plant products. Pure and Applied Chemistry, 66(2), 335-356.

Inoue, T., Nagatomi, Y, Suga, K. Uyama, A., \& Mochizuki, N. (2011). Fate of pesticides during beer brewing. Journal of Agricultural and Food Chemistry, 59(8), 3857-3868.

Jang, J., Rahman, M. M., Ko, A. Y., El-Aty, A. M. A., Park, J. H., Cho, S. K., et al. (2014). A matrix sensitive gas chromatography method for the analysis of pymetrozine in red pepper: Application to dissipation pattern and PHRL. Food Chemistry, 146, 448-454.

Jiang, W., Hu, J., Sun, Z., Gu, F., \& Song, T. (2010). Establishment and application of detection methods for 15 pesticide residues in beer barley. Acta Agriculturae Zhejiangensis, 22(6), 795-801 (in Chinese).

Kondo, K. (2004). Beer and health: preventive effects of beer components on lifestyle-related diseases. BioFactors, 22(1-4), 303-310.

Kong, Z. Q., Dong, F. S., Xu, J., Liu, X. G., Zhang, C. P., Li, J., et al. (2012). Determination of difenoconazole residue in tomato during home canning by UPLC-MS/MS. Food Control, 23(2), 542-546.

Leibovitch, S., Ma, B. L., Maloba, W. E., \& Smith, D. L. (1992). Spring barley responses to row spacing and fungicide triadimefon in regions with a short crop-growing season. Journal of Agronomy and Crop Science, 169(3), 209-215.

Li, H. Z., Zeng, E. Y., \& You, J. (2014). Mitigating pesticide pollution in China requires law enforcement, farmer training, and technological innovation. Environmental Toxicology and Chemistry, 33, 963-971. 
Martin, M. T., Brennan, R. J., Hu, W., Ayanoglu, E., Lau, C., Ren, H., et al. (2007). Toxicogenomic study of triazole fungicides and perfluoroalkyl acids in rat livers predicts toxicity and categorizes chemicals based on mechanisms of toxicity. Toxicological Sciences, 97(2), 595-613.

Matthews, W. A. (1990). Degradation of ${ }^{14} \mathrm{C}$-malathion and ${ }^{13} \mathrm{C}$-chlorpyrifos-methyl on stored wheat. In Proceedings of the final IAEA/FAO research co-ordination meeting on studies of the magnitude and nature of pesticide residues in stored products using radiotracer techniques, Ankara, Turkey, 30 May-3 June 1988 (pp. 73-85). Vienna: IEAE.

Menegola, E., Broccia, M. L., Di Renzo, F., Prati, M., \& Giavini, E. (2000). In vitro teratogenic potential of two antifungal triazoles: triadimefon and triadimenol. Vitro Cellular \& Developmental Biology-Animal, 36(2), 88-95.

Miyake, Y., Hashimoto, K., Matsuki, H., Ono, M., \& Tajima, R. (2002). Fate of insecticide and fungicide residues on barley during storage and malting. Journal of the American Society of Brewing Chemists, 60(3), 110-115.

Navarro, S., Perez, G., Navarro, G., Mena, L., \& Vela, N. (2006). Decay of dinitroaniline herbicides and organophosphorus insecticides during brewing of lager beer. Journal of Food Protection, 69(7), 1699-1706.

Navarro, S., Perez, G., Navarro, G., \& Vela, N. (2007). Decline of pesticide residues from barley to malt. Food Additives and Contaminants: Part A, 24(8), 851-859.

Navarro, S., Perez, G., Vela, N., Mena, L., \& Navarro, G. (2005). Behavior of myclobutanil, propiconazole, and nuarimol residues during lager beer brewing. Journal of Agricultural and Food Chemistry, 53(22), 8572-8579.

Navarro, S., Vela, N., \& Navarro, G. (2011). Fate of triazole fungicide residues during malting, mashing and boiling stages of beer making. Food Chemistry, 124(1), $278-284$.

Navarro, S., Vela, N., Perez, G., \& Navarro, G. (2011). Effect of sterol biosynthesisinhibiting (SBI) fungicides on the fermentation rate and quality of young ale beer. Food Chemistry, 126(2), 623-629.

Navarro, S., \& Vela, N. (2009). Fate of pesticide residues during brewing. In V. R. Preedy (Ed.), Beer in health and disease prevention (pp. 415-428). San Diego CA: Elsevier Inc.

Nelson, M. (2005). The barbarian's beverage: A history of beer in ancient Europe (1st ed.). 0-415-31121-7. Routledge Publisher.

OECD. (2008). OECD guideline for the testing of chemicals. Magnitude of the pesticide residues in processed commodities. NO. 508

Pettersson, D., Graham, H., \& Aman, P. (1991). The nutritive value for broiler chickens of pelleting and enzyme supplementation of a diet containing barley, wheat and rye. Animal Feed Science and Technology, 33(1-2), 1-14.
Phillips, T. W., Berberet, R. C., \& Cuperus, G. W. (2000). Post-harvest integrated pest management. In F. J. Francis (Ed.), Encyclopedia of Food Science and Technology (2nd ed., pp. 2690-2701). New York: Wiley.

Ray, D. E., \& Richards, P. G. (2001). The potential for toxic effects of chronic, lowdose exposure to organophosphates. Toxicology Letters, 120(1-3), 343-351.

Regueiro, J., Lopez-Fernandez, O., Rial-Otero, R., Cancho-Grande, B., \& SimalGándara, J. (2015). A Review on the fermentation of foods and the residues of pesticides-biotransformation of pesticides and effects on fermentation and food quality. Critical Reviews in Food Science and Nutrition, 55(6), 839-863.

Roberts, T. R. (1998). Metabolic pathways of agrochemicals-part 2: Insecticides and fungicides (pp. 360-367). Cambridge, UK: The Royal Society of Chemistry.

Ruediger, G. A., Pardon, K. H., Sas, A. N., Godden, P. W. \& Pollnitz, A. P. (2005). Fate of pesticides during the winemaking process in relation to malolactic fermentation. Journal of Agricultural and Food Chemistry, 53(8), 3023-3026.

Sultatos, L. G. (1994). Mammalian toxicology of organophosphorus pesticides Journal of Toxicology and Environmental Health, 43(3), 271-289.

Tang, Y. L., Xiang, X. J., Wang, X. Y., Cubells, J. F., Babor, T. F., \& Hao, W. (2013) Alcohol and alcohol-related harm in China: Policy changes needed. Bulletin of the World Health Organization, 91(4), 270-276.

Timme, G., \& Walz-Tylla, B. (2004). Effects of food preparation and processing on pesticide residues in commodities of plant origin. In D. Hamilton \& S. Crossley (Eds.), Pesticides residues in food and drinking water: Human exposure and risks (pp. 121-148). Chichester (UK): Wiley.

Tomlin, C. D. S. (Ed.). (2006). The pesticide manual (14th ed. Hampshire, U.K: British Crop Protection Council.

U.S Environmental Protection Agency (US, EPA) (2009). Revised reregistration eligibility decision (RED) for malathion, EPA 738-R-06-030. Washington, DC: U.S Government Printing Office.

Uygun, U., Özkara, R., Özbey, A., \& Koksel, H. (2007). Residue levels of malathion and fenitrothion and their metabolites in postharvest treated barley during storage and malting. Food Chemistry, 100(3), 1165-1169.

Uygun, U., Senoz, B., Ozturk, S., \& Koksel, H. (2009). Degradation of organophosphorus pesticides in wheat during cookie processing. Food Chemistry, 117(2), 261-264.

Zhang, Z., Jiang, W., Jian, Q., Song, W., Zheng, Z., Wang, D., et al. (2015). Residues and dissipation kinetics of triazole fungicides difenoconazole and propiconazole in wheat and soil in Chinese fields. Food Chemistry, 168, 396-403. 